\title{
Assessment of Bone Mineral Density before and after Exercise Training in Postmenopausal Women
}

\author{
Salwa M. EL-BADRY ${ }^{1}$ and Hanan H. FouAD ${ }^{2, *}$ \\ ${ }^{1}$ Obstetric and Gynaecology Department, Faculty of Physical Therapy, \\ Cairo University, Cairo, Egypt \\ ${ }^{2}$ Medical Biochemistry Department, Faculty of Medicine, \\ Cairo University, Cairo, Egypt
}

(Received October 1, 1997)

\begin{abstract}
Summary Bone mineral density (BMD) of lumbar spine (vertebrae 3, 4 , and 5 ) as well as parathormone and estradiol $\left(E_{2}\right)$ levels were studied in two groups of postmenopausal women. The first group A, included 25 subjects who participated in exercise training. The second group B, comprised 15 subjects who did not participate in training. In group A, a significant rise in BMD, a significant decrease in parathormone level and no significant changes in $\mathrm{E}_{2}$ level were observed 6 months after the exercise training. In group $B$, no significant changes in parathormone level or BMD but a significant decrease in $\mathrm{E}_{2}$, were observed 6 months after starting the study.
\end{abstract}

Key Words: bone mineral density, parathormone, estradiol, exercise, osteoporosis

Osteoporosis is more common in women than in men. Postmenopausal bone loss is associated with decrease in female sex hormones as well as with physical inactivity [1]. Calcium supplementation [2], administration of vitamin D [3] or estrogen $[4,5]$, and combination of estrogen and progesterone [6] have been the major prophylactic and therapeutic regimens for bone loss in postmenopausal women.

One of the least costly measures advocated for slowing bone loss in postmenopausal women is regular exercise [7]. Skeletal remodeling is modulated by the availability of calcium, phosphorus and the calcitropic hormones. Exercise has profound effects on body metabolism. It causes significant changes in milieu of the body fluids surrounding the skeleton $[8,9]$.

This work was designed to investigate the effectiveness of exercise training in

* To whom correspondence should be addressed. 
decreasing the rate of bone loss by studying the BMD of the lumbar spine (vertebrae 3, 4, and 5) as well as parathormone $(\mathrm{PTH})$ and estradiol $\left(\mathrm{E}_{2}\right)$ levels in postmenopausal women with and without exercise training.

\section{MATERIALS AND METHODS}

Subjects. This study was conducted on 40 healthy postmenopausal women, at least 5 years after menopause. Their age ranged between 47 to 64 years. None of the subjects had any history of medical diseases or intake of drugs that affect bone metabolism.

Subjects were divided randomly into two groups. Group A included 25 subjects who participated in aerobic exercise training; their mean age was 54.13 $(\mathrm{SD}=4.65)$. Group $\mathrm{B}$ included 15 subjects who did not participate in training, their mean age was $55.30(\mathrm{SD}=5.18)$.

Materials and exercise test procedures.

1. Somaton Hi Q-S (Siemens) Osteo CT scan was used for the quantitative assessment of BMD in the third, fourth, and fifth vertebral bodies of the lumbar spine for both groups A and B.

2. Metabolic Cart (Morgan) and an electronic bicycle ergometer were used to determine the maximum volume of $\mathrm{O}_{2}$ consumption $\left(V \mathrm{O}_{2 \max }\right)$ for each subject in group A.

3. A bicycle ergometer was used to monitor the aerobic exercise training for group A initially at no load (without resistance), and then for $20 \mathrm{~min}$ at the workload that was determined on the basis of $50 \% V \mathrm{O}_{2 \max }$. This was followed by a $10 \mathrm{~min}$ rest period after which each subject in group $\mathrm{A}$ had performed exercises for back extensors and isometric contraction of lumbar flexors through upward and backward pelvic tilting. Sustained muscle contraction was maintained for $5 \mathrm{~s}$ followed by $10 \mathrm{~s}$ of relaxation, and each exercise was repeated 12 times per session. The training program was conducted every other day for 6 consecutive months.

Sample collection. A venous blood sample was taken from each subject before and 6 months after starting the study.

Parameters evaluated.

1. BMD of lumbar spine (vertebrae 3, 4, and 5).

2. Estradiol level.

3. Parathormone level both hormones were assayed by a routine laboratory technique radioimmunoassay [9].

\section{RESULTS}

The results of the study are summarized in Tables 1 and 2 .

Table 1 presents the values of BMD for both groups A and B. BMD showed a significant increase from pre- to post-exercise training in group $\mathrm{A}$, whereas in 
Table 1. BMD (mg Ca $\mathrm{HA} / \mathrm{ml})$ of groups $\mathrm{A}$ and $\mathrm{B}$.

\begin{tabular}{|c|c|c|c|c|}
\hline & \multicolumn{2}{|c|}{ Group A } & \multicolumn{2}{|c|}{ Group B } \\
\hline & Before exercise & $\begin{array}{l}\text { After } 6 \text { months } \\
\text { of exercise }\end{array}$ & Before exercise & $\begin{array}{l}\text { After } 6 \text { months } \\
\text { of the study }\end{array}$ \\
\hline Mean & 112.0 & 141.0 & 115.2 & 114.0 \\
\hline Mean $d$ & \multicolumn{2}{|c|}{29.1} & \multicolumn{2}{|c|}{1.9} \\
\hline $\mathrm{SD} d$ & \multicolumn{2}{|c|}{17.3} & \multicolumn{2}{|c|}{4.3} \\
\hline Probability & \multicolumn{2}{|c|}{$p<0.0001$} & \multicolumn{2}{|c|}{ N.S. } \\
\hline
\end{tabular}

Table 2. Parathormone and estadiol levels in groups $\mathrm{A}$ and $\mathrm{B}$.

\begin{tabular}{|c|c|c|c|c|}
\hline & \multicolumn{2}{|c|}{ Parathormone (ng/liter) } & \multicolumn{2}{|c|}{ Estradiol $(\mathrm{pg} / \mathrm{ml})$} \\
\hline & Group A & Group B & Group A & Group B \\
\hline & $\begin{array}{cc}\text { Before } & \begin{array}{c}\text { After } 6 \\
\text { months of } \\
\text { exercise } \\
\text { exercise }\end{array}\end{array}$ & $\begin{array}{c}\text { Before } \\
\text { After } 6 \\
\text { exercise } \\
\text { months of } \\
\text { the study }\end{array}$ & $\begin{array}{cc}\text { Before } & \text { After } 6 \\
\text { exercise } & \begin{array}{c}\text { months of } \\
\text { exercise }\end{array}\end{array}$ & $\begin{array}{cc}\text { Before } & \text { After } 6 \\
\text { exercise } & \text { months of } \\
\text { the study }\end{array}$ \\
\hline Mean & 12.65 & 14.97 & 3.08 & 2.47 \\
\hline Mean $d$ & -2.37 & 0.68 & 0.42 & -1.56 \\
\hline $\mathrm{SD} d$ & 2.01 & 1.84 & 1.27 & 0.34 \\
\hline Probability & $p<0.001$ & N.S. & N.S. & $p<0.0001$ \\
\hline
\end{tabular}

group $\mathrm{B}$, the changes was insignificant.

Table 2 lists PTH and $\mathrm{E}_{2}$ levels in serum for both groups A and B. In group $A$, a significant decrease in PTH but an insignificant change in $E_{2}$ was observed after 6 months of exercise training. In group B, no significant changes in the PTH level but a significant decrease in $\mathrm{E}_{2}$ was observed 6 months after starting the study.

\section{DISCUSSION}

Osteoporosis is a heterogeneous group of syndromes in which there is a change in bone structure characterized by a reduction in quantity rather than chemical composition, i.e., loss of trabecular bridges which results in mechanical fragility with subsequent fracture and compression with minimal trauma [11].

Several authors have reported the importance of exercise in preventing or minimizing bone loss in postmenopausal women $[12,13]$. Yeh et al. $[14,15]$ found that exercise promoted positive calcium and phosphorus balance and increased skeletal mass after 13 weeks of a running program.

In the current study, the significant increase in bone mineral density of the lumbar spine in group A after exercise training may be explained by piezo electric 
effects as described in physiology textbooks. Compression of bone by physical stress causes a negative potential at the compressed site and positive potential elsewhere in the bone. It has been shown that minute quantities of current flowing in bone causes osteoblastic activity at the negative end of current flow [5].

In the current study, the PTH level in serum exhibited a significant decrease in group A and insignificant change in group B. This observation agrees with the major finding on BMD of the lumbar spine following exercise, i.e., stimulation of osteogenic activity and inhibition of osteoclast maturation. Our results coincide with nearly similar findings obtained by Grimston et al. [16] who reported an increase in calcitonin levels after an exercise program. They concluded that maintenance of skeletal integrity relies on cellular responses to calcitropic hormones and mechanical load stimuli.

In the present study estradiol exhibited insignificant changes in group A, whereas in group B, there was a highly significant decrease. This finding coincides with the results obtained by Gray et al. [17] who reported an increase in the plasma concentration of sex hormone binding globulin and estradiol after an intense interval exercise (treadmill running). These observations may explain the increase in osteoblastic activity and BMD after exercise training.

Also Wolman [18] reported that intensive aerobic exercise can affect BMD indirectly by its effect on hypothalamic-pituitary gonadal axis.

From the present study, we conclude that two exercise regimens conducted for 6 months (program of aerobic training on bicycle ergometer at $50 \% V \mathrm{O}_{2 \max }$ and specific training for the spine in the form of back extension and posterior pelvic tilt exercise) could be therapeutically effective in the prevention of postmenopausal bone loss of the lumbar spine.

\section{REFERENCES}

1. Martin, D., and Notelovitz, M. (1993): Effect of aerobic training on bone mineral density in postmenopausal women. J. Bone Miner. Res., 8 (8), 931-936.

2. Heaney, R., Gallagher, J., Johnston, C., Neer, R., Parfitt, M., Chir, B., and Whedon, D. (1982): Calcium nutrition and bone health in the elderly. Am. J. Clin. Nutr., 36, 986-1013.

3. Edwards, H., Eliot, M., and Sooncharernying, S. (1992): Effect of dietary calcium on tibial dyschondroplasia. Interaction with light, cholecalciferol, 1,25-dihydroxycholecalciferol, protein and synthetic zeolite. Poult. Sci., 71 (2), 2041-2055.

4. Felson, D., Zhang, Y., Hanan, M., Kiei, D., Wilson, P., and Anderson, J. (1993): The effect of postmenopausal estrogen therapy on bone density in elderly women. N. Engl. J. Med., 329 (16), 1141-1146.

5. Guyton, A.C. (1991): Textbook of Medical Physiology, ed. by Guyton, A.C., 8th ed., W.B. Saunders Company, Philadelphia, $610 \mathrm{pp}$.

6. Marslew, U., Overgaard, K., Riis, J., and Christiansen, C. (1992): The new combination of estrogen and progesterone for prevention of postmenopausal bone loss: Long term effects on bone, calcium and lipid metabolism, climacteric symptoms and bleeding. Obstet. Gynecol., 79, 202-210.

7. Bloomfield, S., Williams, N., Lamb, D., and Jackon, R. (1993): Non weight bearing exercise may increase lumbar spine bone mineral density in healthy postmenopausal women. Am.J. 
Phys. Med. Rehabil., 72, 204-209.

8. Menkes, A., Mazie, S., Redmond, R., Koffler, K., Lidanati, C., Gunndberg, C., Zizic, T., Hagberg, J., Partly, R., and Hurlfy, B. (1993): Strength training increases regional bone mineral density and bone remodelling in middle aged and older women. J. Appl. Physiol., 74, 2478-2484.

9. Beaumont, W., Strand, J., Petrofsky, J., Hipskind, S., and Greenleaf, J. (1973): Changes in total plasma content of electrolytes and proteins with maximal exercise. J. Appl. Physiol., 34 (1), 102-106.

10. Henderson, S.A., Graham, R.A., Mollan, R.A.B., Riddoch, C., Sheridan, B., and Johnson, A. (1989): Calcium homeostasis and exercise. Int. Orthop. (Sicot), 13, 69-73.

11. Nathans, H., Adams, P., Weidemann, M., and Haneky, D. (1990): Postmenopausal osteoporosis detection and management. Ann. Int. Med., 102, 38-45.

12. Block, J., Genant, H., and Block, D. (1986): Greater vertebral bone mineral mass in exercising women. West. J. Med., 145, 39-42.

13. Sinaki, M., Wahner, H., Offord, K., and Hodgson, S. (1989): Efficacy of non loading exercise in prevention of vertebral bone loss in postmenopausal women, a controlled trial. Mayo Clin. Proc., 64, 762-769.

14. Yeh, J., Aloia, J., and Yasumura, S. (1989): Effect of physical activity on calcium and phosphorus metabolism in the rats. Am. J. Physiol., 256, E1-E6.

15. Yeh, J., and Aloia, J. (1990): Effect of physical activity on calcitropic hormones and calcium balance in rats. Am. J. Physiol., 258, E263-E268.

16. Grimston, S., Tanguay, K., Gundberg, C., and Haneley, D. (1993): The calcitropic hormone response to changes in serum calcium during exercise in female. J. Clin. Endocrinol. Metab., 76, $867-872$.

17. Gray, A., Telford, R., and Weidemann, M. (1993): Endocrine response to intense interval exercise. Eur. J. Appl. Physiol. Occup. Physiol., 66, 366-371.

18. Wolman, R. (1994): Osteoporosis and exercise. Br. Med. J., 309, 400-403. 